\title{
Advancing Learning and Teaching in the EHEA: Innovation and Links with Research
}

\author{
Michael Gaebel, Thérèse Zhang, and Romita Iucu
}

\section{Learning and Teaching in the European Higher Education Area Context}

\section{Policies, institutions and practice-How are we changing (or not changing)?}

Education, a core mission of universities, is frequently depicted as being resistant towards change regarding teaching methods and forms of provision. As Hooker put it, back in 1997, "the nineteenth-century model of teaching at higher level still holds sway and teaching as not changed much since. The last 15 years have seen progressive developments in many higher education institutions, but the basic model has not altered significantly, at least not in the majority of institutions. Yet the context in which higher education takes place has changed-and changed dramatically" (Hooker 1997).

Is this assertion still true in the modern-day context of the Bologna Process, which, as a continent-wide intergovernmental process, triggered considerable structural reforms across the 48 countries of the European Higher Education Area (EHEA) in the past 20 years?

In the area of learning and teaching, European or national-level policy discussions may be perceived as more or less advanced than realities at higher education institutions, and different from individual academics' daily practice in their classroom. As a matter of fact, over the past years, learning and teaching have emerged as a topic of interest and as a priority, both at institutional and policy levels.

\footnotetext{
M. Gaebel (更) · T. Zhang

European University Association, Brussels, Belgium

e-mail: michael.gaebel@eua.eu

T. Zhang

e-mail: therese.zhang@eua.eu

R. Iucu

University of Bucharest, Bucharest, Romania

e-mail: romita.iucu@unibuc.ro 
At policy level, learning and teaching have become a central topic of discussion when looking towards the future of the EHEA. Whilst the first years of the Bologna Process focused on structural reforms, the Yerevan Communiqué of 2015 marked a shift towards recognising the importance of learning and teaching. With the 2018 Paris Communiqué, the Ministers responsible for Higher Education in the EHEA further emphasised the ongoing transformation of learning and teaching, with a focus on the need to develop participatory and collaborative approaches with the higher education sector and with other stakeholders. The Communiqué pointed to student-centred learning, the diversity of learning methods, flexible learning, better recognition for teaching in academic careers, pedagogical training, increased involvement of students in research or innovation activities and proposed to add innovation in learning and teaching as another hallmark of the EHEA. Several recent and current national initiatives should also be noted, with the common aim to enhance learning and teaching and stimulate a dialogue on teaching enhancement, building on good practices (Bunescu and Gaebel 2018).

The Bologna Process is not the only European policy arena where learning and teaching have recently profiled as a priority. For the European Union, the Renewed Agenda for higher education issued by the European Commission in 2017 also addresses the higher education institutions' contribution to innovation from the perspective of enhanced learning and teaching, with announced measures such as reviewing funding and incentive systems for better rewarding good teaching and increasing possibilities to exchange on the development of pedagogical and curriculum design skills (European Commission 2017). Furthermore, the university consortia selected under the EU's new European Universities Initiatives, launched in 2018, are expected to offer innovative, student-centred curricula which enable seamless mobility and push towards better synergies between education, research and innovation.

At the level of higher education institutions (HEIs), the European University Association (EUA)'s Trends 2018 report, which is based on an extensive survey on learning and teaching at HEIs across the EHEA, showed that diverse and interesting experiences and developments are taking place (Gaebel and Zhang 2018). The findings also confirmed that, while the dynamics for change and transformation come from learning and teaching practice, their sustainability and success depend on institutional and, to some extent, on system-level strategies and support. This is acknowledged in the Paris Communiqué, which highlights exchange and collaboration among European HEIs are an important catalyst for change, with a specific reference to EUA's annual European Learning and Teaching Forum launched in 2017 as a platform for collaboration in learning and teaching.

At individual teachers' level, the Trends 2018 report demonstrated that "those with responsibility in teaching" encompass a broad range of staff with different profiles, ranging from full professors to practitioners in specific fields and researchers. Teaching also relies on teaching support staff, staff providing technical support and student services. Teaching enhancement, in the form of initial training in didactics and pedagogy as part of doctoral training or as continued professional development is increasingly emphasis ed at (national) system level, but its actual development and implementation lie mostly with the higher education institutions. While teaching per- 
formance is commonly evaluated, more suitable evaluation instruments are still being explored, and, importantly, evaluation results have little or no impact on academic career progression. In other words, across the EHEA and with a few exceptions, good teaching currently receives no or very little recognition. Institutions identify the lack of recognition for teaching in individual career progression as one of the top obstacles for improving learning and teaching.

In conclusion, further enhancement of learning and teaching is a relatively complex endeavour which requires that policy, institutional and individual levels operate closely together. The 2020 Bologna Process Researchers' Conference addressed "Advancing learning and teaching: innovation, links with research, and cooperation with the European Research Area (ERA)" as one of its thematic sessions, and papers attached to this theme highlighted several interesting aspects of this cooperation.

\section{The 2020 Bologna Process Researchers' Conference: three directions to explore}

Four papers are published under this theme:

- Mihaela V. Cărăuşan, in The integration of experiential learning in higher education institutions - an assessment of the Romanian universities, advocates for a better integration of experiential learning at Romanian higher education institutions. Her analysis of experiential learning as a game-changing pedagogical approach to address traditional teaching in higher education is based on a literature review as well as a comparative analysis of official documentation for study programmes at several Romanian universities. The paper offers a reflection on the overall relevance of, and need for, a renewed approach to university pedagogy.

- With Recognizing student activism: Analysing practices in recognising informal learning in the EHEA, Marita Gasteiger and Janine Wulz advocate for more systematic recognition of student engagement as a form of informal learning across the EHEA. From surveys conducted among student representatives at both institutional and national levels in 10 EHEA countries, the authors identify best practices, challenges and lessons learnt on recognition of informal learning.

- In Closing the circle. Research and policy making in education, Simona Iftimescu, Georgeta Ion, Carmen Proteasa, Romita Iucu, Elena Marin and Mihaela Stingu address the mechanisms of research uptake and utilization in the planning, implementation and evaluation of education policies in Romania. The paper is based on a survey among civil servants in the Romanian national administration. The authors analys e organizational factors likely to affect research uptake, such as the research culture among policy makers, engagement with researchers, and the political, managerial and financial context that impact on research transfer. As a conclusion, the paper emphasis es the growing need to enhance partnerships between policymakers and researchers, based on high-quality research, transparency and social responsibility.

- Finally, for their paper Assessing students' perspective on teaching and learning. The case of national students' surveys, Ştefan Marius Deaconu, Roland Olah and Cezar Mihai Haj conducted an extensive study on the impact of national student surveys on learning and teaching, with a focus on the cases of Norway, Romania 
and the United Kingdom. The authors analyse which structures are required and how stakeholders are involved in developing and coordinating national student survey processe, and the selection of topics addressed in the questionnaires. The paper concludes on how such surveys document students' perceptions of education reforms and can contribute to evidence-based decisions on learning and teaching.

The topics explored in these papers point to three directions, which would qualify as trends in the EHEA policy discussions as well as at European higher education institutions:

- the multiplicity of changing approaches and practices in learning and teaching

- the complex relation between teaching and research, including the contribution of research to evidence-based teaching and education policies

- the importance of teaching as core to the academic practice, and its scholarly and professional recognition.

All three trends may entail significant changes and paradigm shifts for the future of higher education learning and teaching. The following sections offer a brief analysis for each of them.

\section{Changing Approaches in Learning and Teaching}

Student-centred learning (SCL) has been a goal of the Bologna Process since its early years. However, until 2012-2015, this did not lead to discussions on didactics and pedagogy but focused on structural reforms such as ECTS implementation. Besides, the concept of SCL remains difficult to grasp in practice and across European higher education institutions (Gaebel and Zhang 2018: 53-54; Loukkola and Dakovic (eds.) 2017), although the European policy level has been promoting it for years.

In addition to increasing students' academic performance and retention, this also brought up more pedagogical aspects such as student motivation, active learning and the role of the university teacher as a learning facilitator (Christersson et al. 2019). As Hannon (2009) already put it, "far from the role of teacher becoming redundant as learning becomes democratised, it is likely that the skill set of the professional educator will shift towards expertise in pedagogy: understanding with precision how people learn, and how learning opportunities need to be designed to facilitate this process." In this regard, and although teaching may still be perceived mostly as an individual activity and responsibility, the Trends 2018 report showed that teaching, nowadays, should also be looked at as a collective process and responsibility. Individual teachers do play an important role in deciding what teaching methods to use; yet, they also rely on collaboration and support, including from pedagogical coordination at faculty, department or study programme levels (Gaebel and Zhang 2018: 56-58). This is crucial, considering that the curriculum should open up to different learning methods, based on a learning outcome and the constructive alignment approach.

Another aspect is to examine how experimentation and innovation change approaches to learning and teaching. As Henderikx and Jansen (2018) put it, there is 
expectation across the EHEA on "a time when the new ideas on models of learning, on interdisciplinarity, integrated learning, team pedagogy, on deep learning, etc., will be mainstreamed". The Organisation for Economic Co-operation and Development (OECD) also addressed the importance of innovative pedagogies, provided a conceptual framework to cluster them and cited examples of practices such as experiential learning (Panigagua and Istance 2018).

Furthermore, changing approaches to learning and teaching also respond to changing skills needs, demographic developments and increased diversity of the student population. The assumption is that lifelong learning would become more commonalthough it may take various shapes, depending on the institutions' missions, profile and their national and regulatory environments (Smidt and Sursock 2011). This entails adequate relations and recognition mechanisms between formal and informal learning experiences gained throughout lifetime and further attention towards to inclusiveness of the classroom - to cite these points among others. Inclusive education should address not only equal access but also the overall student learning experience, ${ }^{1}$ which ranges from learning environment design to behaviour patterns among student populations or adequate assessment for learning outcomes. ${ }^{2}$ In turn, and provoked by changing institutional practice, European policy circles recently started paying more interest to pedagogy, with a focus on innovation in learning and teaching. The Paris Communiqué of the Bologna Process, for instance, provides concrete examples of approaches such as work-based learning and makes a plea for enhancing pedagogical training for teachers (Paris Communiqué 2018).

From the 2020 Bologna Process Researchers' Conference, two papers address these changing approaches to learning and teaching, from two different and complementary angles:

- In Recognizing student activism. Analyzing practices in recognizing informal learning in the EHEA, Gasteiger and Wulz take the case of student activism to address how recognition for informal learning take place at European higher education institutions. The co-authors advocate for EHEA countries to develop national policies and regulations in this regard, with due attention to the diversity of learning experiences that can be recognised as informal learning.

- In The integration of experiential learning in higher education institutions. An assessment of the Romanian universities, Cărăuşan provides a theoretical and analytical contribution to the use of experiential learning in Romanian higher education. The paper shows that a paradigm shift in pedagogy is much needed, for education provision to better prepare students for competences needed beyond university.

\footnotetext{
${ }^{1}$ See, for instance, The National Forum for the Enhancement of Teaching and Learning in Higher Education (2019). 'Making a difference'. A student view of excellent teaching, and Understanding and enabling student success in Irish Higher Education, Dublin, National Forum for the Enhancement of Teaching and Learning.

${ }^{2}$ See, for instance, Hannon, 2009.
} 


\section{The Complex Relation Between Research and Teaching}

The Bologna Process primarily targets education and has mostly left out research as another core mission of universities. However, in the two last Communiqués (2015 and 2018), better synergies between education and research were highlighted as a priority for the EHEA. Learning, teaching and research should be interconnected and mutually enriching, and this connection is essential to stimulate innovation and creativity in the learning experience and to advance knowledge. ${ }^{3}$ As a recent empirical study shows, when research is integrated into the teaching activity, students are more motivated and interested in how to develop research and, generally, have a better perception of their learning environment (Milescu 2019).

However, the nexus between teaching and research is complex to explore, with different understandings of concepts such as research-based and research-led learning. The implementation of practices connecting teaching and research may also vary depending on disciplines and perceptions among academic staff. Jenkins, Healey and colleagues proposed several definitions in this regard, based on different types of engagement between students and research, and different positionings of the teacher, ranging from the teacher being at the centre of a process focusing on understanding research findings (research-led teaching), to a focus shift on the students' systematic exploration activities (research-tutored teaching) (Jenkins et al. 2007).

Even equipped with definitions from literature, HEIs and individual teachers may struggle in finding an overall coherence between different approaches. The links between research and learning and teaching can be weak even within researchintensive institutions with limited or no institution-driven, strategic approaches for the integration of research and education missions. Differences can also be noted in the type of opportunities offered to students for engaging with research, ranging from bachelor programmes integrating such opportunities to initiatives targeting selected students at graduate level only. In several higher education systems, frameworks for research and teaching have been set up in such a way that academics tend to separate their activities as researchers in labs and teachers in the classroom (Dakovic and Loukkola eds. 2017: 4-8).

Finally, another aspect of the nexus between education and research is how research may inform learning and teaching, and data derived from research contributes to nurture the teaching culture. According to the Trends 2018 report, twothirds of institutions surveyed across the EHEA conduct systematic research on learning and teaching, through academic research in education sciences (for half of the institutions), institutional learning and teaching centres, and other initiatives (Gaebel and Zhang 2018: 20-21). However, additional studies would be needed to assess the actual impact of such research.

Under the 2020 Bologna Process Researchers' Conference, a paper addressed the interconnection between research and teaching, both from the policy perspective:

\footnotetext{
${ }^{3}$ As phrased under the Ten European Principles for the Enhancement of Learning and Teaching (EFFECT project) (2018). http://bit.ly/EFFECTproject.
} 
- In Closing the circle. Research and policy making in education, Iftimescu and co-authors analyse the factors for interaction between educational researchers and policymakers and make a case for a more fluent communication among them. The paper underlined the importance of trust in education research as a critical factor in understanding the dynamics of research uptake in policy making. The results of the authors' survey demonstrate that, even without strong national regulations requesting evidence-based decisions, policy makers highly value the contribution of research in informing decisions in education policies. Among other conclusions, the paper advocates a stronger emphasis on knowledge management in public administration and partnerships between those in charge of knowledge production and those who use it. Iftimescu and co-authors show that, although a fundamental mission and core activity at universities, research is still not sufficiently used for informing decisions regarding the education provision, at national and institutional levels.

\section{The Importance of Teaching as Core to the Academic Practice}

As Sir Roderick Floud put it, "there is no contradiction between the imperative of good teaching and the imperative of research which critiques, refines, discards and advances human knowledge and understanding. A good teacher, like a good graduate, is also an active learner, questioner and critical thinker. The good teacher aims to help the student be confident in handling the subject as it has developed so far, to be courageous in openness to new ideas (...)" (Standing Committee for the Social Sciences 2015). However, for such good teaching to happen and for teachers to lead pedagogical change, better recognition is needed for teaching in the academic world. Indeed, HEIs identify the lack of recognition for teaching in career progression (Gaebel and Zhang 2018: 62) and, more generally, the imparity of esteem between research and teaching as a key obstacle for improving learning and teaching. The issue has also been repeatedly highlighted by the twelve thematic peer groups of universities organised by the European University Association from 2017 onwards. ${ }^{4}$ As a core function of higher education, teaching should be recognised as a professional and academic activity to be actively promoted through recruitment, staff development (including continuing professional development) and promotion schemes. Staff members with teaching responsibilities should benefit from support in fulfilling their role and in developing their skills and practices to meet changing circumstances. ${ }^{5}$ The EU High Level Group on the Modernisation of Higher education (2014) also underlined the growing importance of improving learning and teaching and making more visible the educational research towards improving teaching abilities, for

\footnotetext{
${ }^{4}$ https://www.eua.eu/issues/20:learning-teaching.html (02/03/2020).

${ }^{5}$ As phrased under the Ten European Principles for the Enhancement of Learning and Teaching (EFFECT project) (2018). http://bit.ly/EFFECTproject.
} 
instance through teacher development programmes. "We have almost 4000 higher education institutions in Europe, of all shapes and sizes", the EU High Level Group noted. "These institutions, for all their differences, share a crucial task and a crucial responsibility - to teach our young (and also our not so young) people, and to teach them to the best level possible."

The Trends 2018 report noted that teaching enhancement is often emphasised at the system level, but its actual development and implementation lies mostly with the higher education sector, with $77 \%$ of HEIs surveyed providing optional teaching enhancement courses, and two-thirds also encouraging and supporting good teaching through other means, such as portfolios, self-evaluations, peer feedback, team-teaching, and, more generally, encouragement for scholarship of learning and teaching (Gaebel and Zhang 2018: 71-76). Most HEIs also confirmed that national and international initiatives, supported by governments or by the higher education sector itself, are very useful in the development of teaching enhancement-although only approximately half of Trends 2018 respondents indicated that a national-level learning and teaching strategy prompted them to introduce or increase teaching enhancement and that they cooperate on teaching enhancement through participation in national initiatives.

Several papers under the 2020 Bologna Process Researchers' Conference relate to the professionalisation of teaching in higher education and mention the importance of training and continued professional development for teachers. In particular, Assessing students' perspective on teaching and learning. The case of national students' surveys describes and analyses how a national student survey contributes to making teaching standing out as a core mission and obligation of higher education institutions. Deaconu and co-authors also emphasised the importance of national (and European) attention into teaching, and how, ultimately, results from such national student surveys can contribute to informing and shaping education policies.

\section{Conclusions: Advancing Learning, Teaching... and Its Interconnection with Research}

Higher education institutions are increasingly expected to innovate learning and teaching, to enable students to acquire the necessary professional and civic skills and to respond to the society's demand for qualified graduates and global citizens. In order to so, the European and national policy level, the institutional level, and the individual practice level need to better connect and engage together in a shared commitment towards enhancing learning and teaching. Research on education policies and practices also takes an important role in contributing to this dialogue. The Bologna Process Researchers' Conference is one opportunity for establishing this connection, at the interface between policy making, research and practice. 


\section{References}

Ten European Principles for the Enhancement of Learning and Teaching (EFFECT project) (2018). http://bit.ly/EFFECTproject.

Bunescu, L., \& Gaebel, M. (2018). National initiatives in learning and teaching in Europe. A report from the European Forum for Enhanced Collaboration in Teaching (EFFECT) project, Brussels, EUA. https://www.eua.eu/resources/publications/799:national-initiatives-in-learningand-teaching-in-europe.html (26/02/2020).

Christersson, C., Straaf, P., Peterbauer, H., \& Zhang, T. (2019). Promoting active learning in universities. Thematic Peer Group Report. Brussels, EUA, Learning and Teaching Papers \#5.

EU High Level Group on the Modernisation of Higher Education (2014). Report to the European Commission on Improving the quality of teaching and learning in Europe's higher education institutions http://ec.europa.eu/dgs/education_culture/repository/education/library/reports/ modernisation_en.pdf_(26/02/2020).

European Commission (2017), Communication from the Commission to the European Parliament, the Council, the European Economic and Social Committee, and the Committee of the Regions, on a renewed EU agenda for higher education. $\operatorname{COM(2017)247~final.~https://eur-lex.europa.eu/~}$ legal-content/EN/TXT/?uri=CELEX\%3A52017DC0247(26/02/2020).

Gaebel, M. \& Zhang, T. (2018). Trends 2018: Learning and teaching in the European Higher Education Area, Brussels, EUA. https://eua.eu/downloads/publications/trends-2018-learningand-teaching-in-the-european-higher-education-area.pdf (26.02.2020).

Henderikx, P., \& Jansen, D. (2018). The Changing Pedagogical Landscape. In search of patterns in policies and practices of new modes of teaching and learning, Maastricht, EADTU.

Hooker, M. (1997). The transformation of higher education. In Oblinger, D. \& Rush, S. (Eds.) (1997). The Learning Revolution. Bolton, MA, Anker Publishing Company, Inc.

Jenkins, A., Healey, M., \& Zetter, R. (2007). Linking Research and Teaching in Disciplines and Departments. York, Higher Education Academy.

Joosten, T. (2015). Research to Ensure Access and Success in Higher Education, Published on EDUCAUSE Review, (13/04/2015).

Loukkola, T., \& Dakovic, G, Eds. (2017), EUA's Learning and Teaching Initiative. Reports from the thematic peer groups, Brussels, EUA. https://www.eua.eu/resources/publications/348:eua $\% \mathrm{E} 2 \% 80 \% 99 \mathrm{~s}$-learning-and-teaching-initiative-report-from-the-thematic-peer-groups.html (26/02/2020).

Miulescu, M. L. (2019). The Relationship Between Research and Teaching: Assessing the Students' Perceptions in The Context of A New Evaluation Methodology. Revista de Pedagogie, 67(2), 125-137. https://doi.org/10.26755/RevPed/2019.2/125 (26/02/2020).

Panigagua, A., \& Istance, D. (2018). Teachers as Designers of Learning Environments: The Importance of Innovative edagogies. Educational Research and Innovation, Paris, OECD Publishing, https://read.oecd-ilibrary.org/education/teachers-as-designers-of-learningenvironments_9789264085374-en\#page4_(02/03/2020).

Paris Communiqué of the Bologna Process (2018). http://www.ehea.info/Upload/document/ ministerialdeclarations/EHEAParis2018Communique_final952771.pdf_(26/02/2020).

Smidt, H. \& Sursock, A. (2011). Engaging in Lifelong Learning: Shaping Inclusive and Responsive University Strategies, Brussels, European University Association. (2/03/2020).

Standing Committee for the Social Sciences (SCSS) (2015). The Professionalisation of Academics as Teachers in Higher Education, Science Position Paper, www.esf.org/social_ (26/02/2020). 
Open Access This chapter is licensed under the terms of the Creative Commons Attribution 4.0 International License (http://creativecommons.org/licenses/by/4.0/), which permits use, sharing, adaptation, distribution and reproduction in any medium or format, as long as you give appropriate credit to the original author(s) and the source, provide a link to the Creative Commons license and indicate if changes were made.

The images or other third party material in this chapter are included in the chapter's Creative Commons license, unless indicated otherwise in a credit line to the material. If material is not included in the chapter's Creative Commons license and your intended use is not permitted by statutory regulation or exceeds the permitted use, you will need to obtain permission directly from the copyright holder. 